\title{
Fatigue and Fracture Behavior of Cryogenic Materials Applied to LNG Fuel Storage Tanks for Coastal Ships
}

\author{
Tae-Yeob Kim ${ }^{1}{ }^{\mathbb{D}}$, Sung-Won Yoon ${ }^{1, *}$, Ji-Hoon Kim ${ }^{2}$ and Myung-Hyun Kim ${ }^{2}$ \\ 1 Advanced Materials \& Components Research Center, Research Institute of Medium \& Small \\ Shipbuilding (RIMS), Busan 46757, Korea; tykim@rims.re.kr \\ 2 Department of Naval Architecture and Ocean Engineering, Pusan National University, Busan 46241, Korea; \\ wlgns3417@pusan.ac.kr (J.-H.K.); kimm@pusan.ac.kr (M.-H.K.) \\ * Correspondence: swyoon@rims.re.kr; Tel.: +82-51-974-5567
}

Citation: Kim, T.-Y.; Yoon, S.-W.; Kim, J.-H.; Kim, M.-H. Fatigue and Fracture Behavior of Cryogenic Materials Applied to LNG Fuel Storage Tanks for Coastal Ships. Metals 2021, 11, 1899. https:// doi.org/10.3390/met11121899

Academic Editors: Mauro Madia and Luis Filipe Borrego

Received: 15 October 2021

Accepted: 19 November 2021

Published: 25 November 2021

Publisher's Note: MDPI stays neutral with regard to jurisdictional claims in published maps and institutional affiliations.

Copyright: (c) 2021 by the authors. Licensee MDPI, Basel, Switzerland. This article is an open access article distributed under the terms and conditions of the Creative Commons Attribution (CC BY) license (https:// creativecommons.org/licenses/by/ $4.0 /)$.

\begin{abstract}
The aim of this study is to investigate the applicability of automatic plasma arc welding (PAW) to cryogenic materials used in liquefied natural gas (LNG) fuel storage tanks based on experimental data. The mechanical properties of the materials were tested at room and cryogenic temperatures to investigate the fatigue and fracture performances of weld joints made by PAW. In addition, the influence of welding parameters on the welded joints such as material types and temperature were considered in this experimental study. Based on the results obtained by this experimental study, it was observed that the experimental results of all materials at room and cryogenic temperatures satisfied all the requirements of each mechanical test. Finally, we propose the experimental results of PAW that can be used in the structural design of LNG fuel storage tank applications.
\end{abstract}

Keywords: plasma arc welding (PAW); cryogenic materials; liquefied natural gas (LNG)

\section{Introduction}

According to Regulation 14 in MARPOL 73/78 Annex VI of the International Maritime Organization (IMO), 1 January 2020 has been set as the implementation date to significantly reduce the sulfur content of fuel oil used by ships [1]. In response to this mandate, LNGfueled ships that use liquefied natural gas (LNG) have been introduced, with LNG emerging as the best alternative marine fuel to satisfy environmental regulations as well as the most ideal method compared to existing fuels used on ships.

An LNG storage tank is mainly made of low-temperature materials with excellent fracture toughness that can operate safely under a cryogenic environment. Furthermore, many studies have examined the fatigue and fracture performance of various lowtemperature materials, such as austenitic stainless steel (ASS), aluminum, invar alloy, and high-manganese and nickel steel.

Currently, the most widely used cryogenic material for LNG tanks is nickel alloy steel: $9 \%$ nickel steel is generally used at cryogenic temperatures, and the low-temperature toughness of this steel is more important than toughness at room temperature. It also has excellent mechanical properties at cryogenic temperatures. However, nickel steel was produced in a limited number of countries, and its supply was unstable. Accordingly, price fluctuation in the market was a major issue depending on the supply and demand.

Shielded metal arc welding (SMAW) and submerged arc welding (SAW) are mainly applied to the welding method for $9 \%$ nickel steel. In the case of flux-cored arc welding (FCAW), welding consumables for 9\% nickel steel were developed. However, there are few cases applied to real structures. The research trends related to this are reviewed as follows. For example, Saitoh et al. evaluated the mechanical properties of $9 \% \mathrm{Ni}$ steel while considering various welding processes and consumables [2]. Yoon et al. evaluated the fatigue crack growth rate (FCGR) of newly developed $35 \mathrm{~mm}$ thick $9 \% \mathrm{Ni}$ steel [3]. Using 
shielded metal arc welding (SMAW), submerged arc welding (SAW), and flux-cored arc welding (FCAW), Kim et al. studied the fracture toughness of $9 \%$ nickel steel with a focus on the welding processes and consumables used. In addition, the initial structural design of the LNG fuel tank was carried out, and the correlation between the groove angle and weld penetration shape was investigated [4,5]. Kim et al. studied the penetration characteristics of laser beam welding (LBW) according to the welding speed and power. In addition, Kim et al. compared the effects of the mechanical properties of the weld zone between LBW and FCAW on cryogenic temperatures, such as tensile/yield strength, hardness, bending strength, and impact property [6,7]. In another study, Oh et al. (2006) studied the fatigue performance of welded joints using SUS 304L and Invar alloy at ambient and cryogenic temperatures, respectively [8].

The high manganese steel developed by POSCO has high production rates around the globe and is relatively inexpensive. It is applied to various industries based on various properties such as cryogenic toughness, high strength, high damping, non-magnetic, and high formability depending on components such as Mn and C. In addition, it is about 30\% cheaper than $9 \%$ nickel steel and is competitive enough to replace existing materials. Several studies have examined the application of high-manganese steel at cryogenic temperatures. For example, Choi et al. discussed the tensile properties, CTOD, Charpy impact energies, and fatigue and corrosion performances of high-manganese steel sheets and welded joints at both room and cryogenic temperatures [9]. Fan et al. investigated the mechanical properties of high-manganese steel welded with nickel-based welding materials using SMAW and SAW [10]. The comprehensive properties of SMAW are better than those of SAW. Seo et al. evaluated the mechanical property and fatigue behavior of high manganese steel with the content of $\mathrm{Mn}$ ranging from 16 to $25 \mathrm{wt} \%$ [11]. Jeong et al. studied the fatigue behavior of Fe15Mn austenitic steel, including base metal and butt-welded joints, at 298 $\mathrm{K}$ and $110 \mathrm{~K}$; these results were compared to those of 304L stainless steel [12]. Park et al. compared the fracture toughness values of high-manganese steel and $304 \mathrm{~L}$ stainless steel at various temperatures (298-77 K). The high-manganese steel exhibited excellent fracture toughness at both ambient and cryogenic temperatures, with values comparable to those of 304L stainless steel [13]. Park et al. investigated the effect of post-weld processes including the microstructure and mechanical properties of high-manganese steel sheets fabricated by gas tungsten arc welding (GTAW). In the results of this study, the hardness and strength were lower than that of the base metal at the weld zone, which is explained by the coarser grain size $[14,15]$. Fatima et al. studied the optimization of process parameters for plasma arc welding for dissimilar metals such as austenitic stainless steel and low carbon steel. In particular, they investigated the effects of welding current and speed on the quality of welded joints [16]. The mechanical properties of welded joints, which are closely related to cryogenic materials, have been extensively investigated by many researchers.

The plasma arc welding (PAW) process uses a highly constricted arc to produce a keyhole inside the weld pool. It also features high levels of accuracy, weldability, and a narrow heat-affected zone (HAZ). With these advantages, PAW has been used in a wide range of applications for the joining of metals in manufacturing industries [17]. Therefore, the application of plasma arc welding can drastically reduce the time to manufacture LNG fuel storage tanks. However, plasma arc welding (PAW) for cryogenic materials has little or no field applications. There have also been few studies investigating cryogenic materials associated with PAW and fewer comparative studies considering high manganese steel and $9 \%$ nickel steel for the plasma arc welding processes.

The aim of this study is to investigate the applicability of automatic plasma arc welding (PAW) to cryogenic materials in LNG fuel storage tanks. To this end, this study compared the fatigue and fracture performances of high-manganese steel and $9 \%$ nickel steel according to the automatic plasma arc welding processes at room $\left(298 \mathrm{~K}, 25^{\circ} \mathrm{C}\right)$ and cryogenic $\left(110 \mathrm{~K},-163^{\circ} \mathrm{C}\right)$ temperatures. 


\section{Materials and Test Methods}

\subsection{Materials}

In this work, an experimental study was conducted to apply automatic plasma arc welding to high-manganese steel and 9\% nickel steel, which are both used to produce LNG fuel storage tanks for coastal ships. The materials used in this paper are Fe-9Ni steel (hereinafter referred to as "9\% Ni, 9\% nickel steel and ASTM A553 Type 1") and carbon-manganese steel (hereinafter referred to as "high Mn or high-manganese steel"). These materials are listed in the International Code of the Construction and Equipment of Ships Carrying Liquefied Gases in Bulk (IGC Code) adopted by IMO by resolution MSC.5 (48).

The chemical composition of base metal used in this study is shown in Table 1 . It can be seen from the chemical composition that the Ni content of $9 \%$ Ni steel is $9.02 \%$, and the Mn content of high Mn steel is 22.0 to $26.0 \%$. Table 2 shows the mechanical properties of nickel alloy steels and austenitic manganese alloy steels for low-temperature service. ASTM A1106/A1106M and DNV-RU-SHIP Pt.2 Ch.2 also suggest that for materials complying with recognized standards, the mechanical properties shall satisfy the requirements of the relevant standards and grades $[18,19]$. The values for yield strength, tensile strength, and elongation specified in Table 2 have been obtained at room temperature.

Table 1. Chemical composition of base metal.

\begin{tabular}{cccccccc}
\hline Material & $\mathbf{C}$ & $\mathbf{M n}$ & $\mathbf{S i}$ & $\mathbf{S}$ & $\mathbf{P}$ & $\mathbf{N i}$ & $\mathbf{F e}$ \\
\hline $9 \% \mathrm{Ni}$ & 0.05 & 0.004 & 0.67 & 0.003 & 0.25 & 9.02 & Bal. \\
\hline Material & $\mathbf{C}$ & $\mathbf{M n}$ & $\mathbf{S i}$ & $\mathbf{S}$ & $\mathbf{C r}$ & $\mathbf{N}$ & \\
\hline High Mn & $0.35-0.55$ & $22.0-26.0$ & 0.3 & 0.01 & $3.0-3.5$ & 0.05 & \\
\hline
\end{tabular}

Table 2. Mechanical properties for low-temperature service [18,19].

\begin{tabular}{|c|c|c|c|c|c|c|c|c|}
\hline \multirow[b]{2}{*}{ Material } & \multirow[b]{2}{*}{$\begin{array}{l}\text { Tensile } \\
\text { Strength } \\
\text { (MPa) }\end{array}$} & \multirow[b]{2}{*}{$\begin{array}{l}\text { Min. Yield } \\
\text { Strength } \\
\text { (MPa) }\end{array}$} & \multirow[b]{2}{*}{$\begin{array}{c}\text { Min. } \\
\text { Elongation } \\
(\%)\end{array}$} & \multicolumn{4}{|c|}{ Charpy V-Notch Impact } & \multirow[b]{2}{*}{$\begin{array}{c}\text { Min. Design } \\
\text { Temperature } \\
\left({ }^{\circ} \mathrm{C}\right)\end{array}$} \\
\hline & & & & $\begin{array}{l}\text { Thickness } \\
(\mathrm{mm})\end{array}$ & $\begin{array}{c}\text { Test } \\
\text { Temperature } \\
\left({ }^{\circ} \mathrm{C}\right)\end{array}$ & $\begin{array}{c}\text { Min. } \\
\text { Transverse } \\
\text { (J) }\end{array}$ & $\begin{array}{c}\text { Min. } \\
\text { Longitudinal } \\
(\mathrm{J})\end{array}$ & \\
\hline $9 \% \mathrm{Ni}$ & $640-840$ & 490 & 19 & $\mathrm{t} \leq 40$ & -196 & 27 & 41 & -165 \\
\hline High Mn & $800-970$ & 400 & 22 & $\mathrm{t} \leq 40$ & -196 & 27 & 41 & -165 \\
\hline
\end{tabular}

Figure 1 shows the LNG fuel storage tank being developed through R\&D cooperation with various domestic companies. Typical LNG fuel storage tanks need to be fabricated either by a longitudinal seam (L-Seam) or circumferential seam (C-Seam) weld joining process. Figure 1 shows a schematic diagram in LNG fuel storage tanks where the location of the C-Seam and L-Seam welds are indicated. The number of shells changes depending on the capacity of the tank and the customer's requirements. Table 3 summarizes the welding process parameters considered in this study.

Table 3. Welding parameters of weld metals.

\begin{tabular}{ccccc}
\hline Welding Process & $\begin{array}{c}\text { Voltage } \\
\text { (V) }\end{array}$ & $\begin{array}{c}\text { Current } \\
\text { (A) }\end{array}$ & $\begin{array}{c}\text { Welding Speed } \\
\text { (cm/min) }\end{array}$ & Shielding Gas \\
\hline Plasma arc welding & 350 & 27 & 60 & $\mathrm{Ar}$ \\
\hline
\end{tabular}




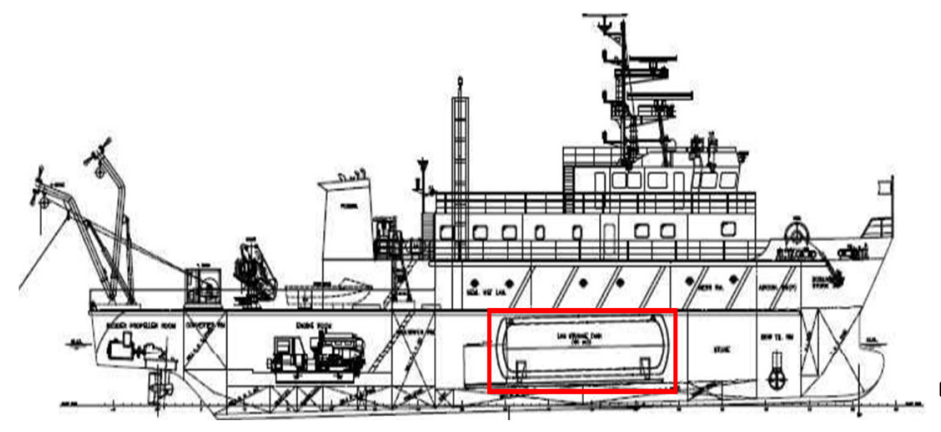

(a)

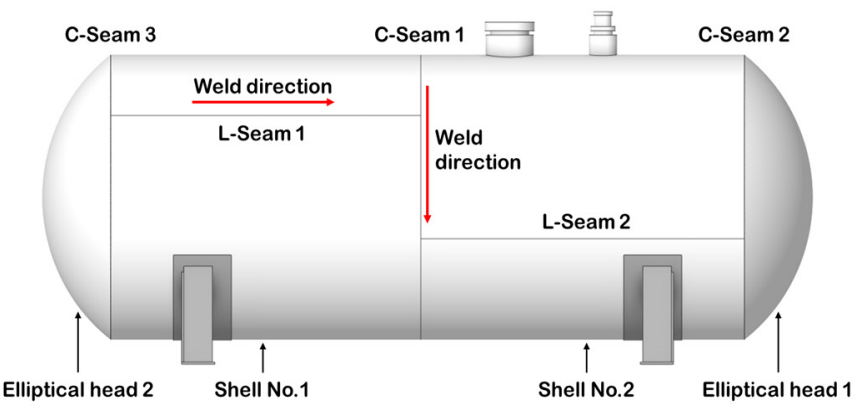

(b)

Figure 1. The welding configuration of the LNG fuel tanks in LNG-fueled ships: (a) concept of general arrangement design; (b) schematic diagram of the LNG fuel storage tanks.

\subsection{Testing Machine}

The mechanical properties of the materials were tested at room and cryogenic temperatures to assess the applicability of each material for LNG fuel storage tanks. The test equipment used in this study was a servo-hydraulic testing machine (IMT 8803, IST 8800 of Instron Corporation) with a maximum load capacity of $\pm 500 \mathrm{kN}$. In addition, the chamber is controlled in a cryogenic environment, and the test temperature is maintained by a liquid nitrogen gas inlet and outlet control system. Figure 2 shows the total equipment setup for the mechanical properties testing, including the extensometer used for the tensile test and the COD gauge used for the crack tip opening displacement (CTOD) test and fatigue crack growth (FCG) test.

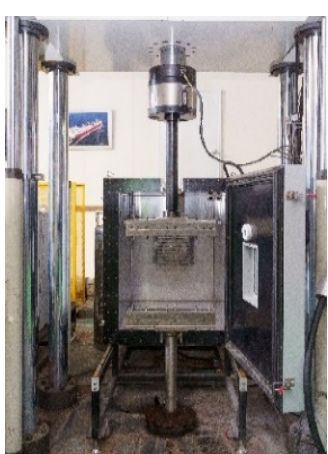

(a)

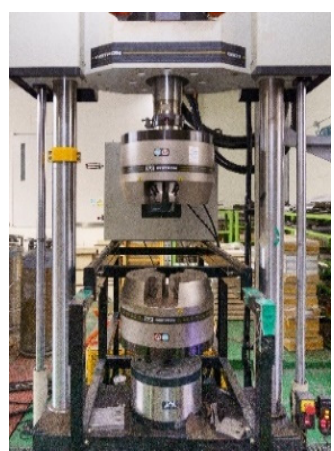

(b)

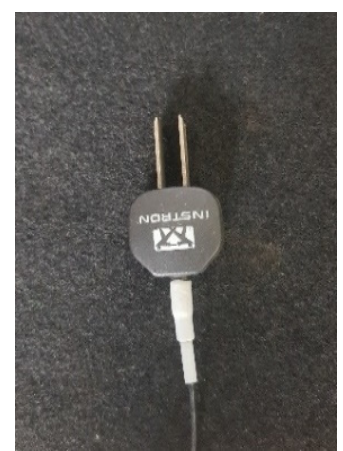

(c)

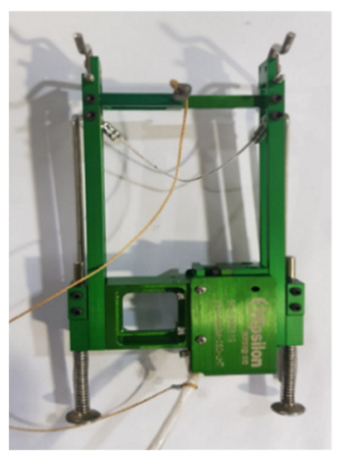

(d)

Figure 2. Testing machine: (a) IST 8800; (b) IMT 8803; (c) COD gauge; (d) Extensometer.

\subsection{Test Scope}

This section specifies methods for the mechanical testing of materials and defines the mechanical properties that can be determined at room and cryogenic temperatures. The scope of the mechanical properties testing in Table 4 includes all materials and tests mentioned in this study. All tests were conducted at room temperature $\left(298 \mathrm{~K}, 25^{\circ} \mathrm{C}\right)$ and cryogenic temperature $\left(110 \mathrm{~K},-163^{\circ} \mathrm{C}\right)$.

\subsection{Tensile Test}

A tensile test was performed to measure the mechanical properties of the cryogenic materials according to ASTM E8/E8M standards [20]. ASTM E8/E8M is a tensile test standard for measuring yield strength, tensile strength, elongation, etc., and it suggests different types of test methods for various types of specimen shapes, such as plate, sheet, and round. 
Table 4. The scope of the mechanical properties testing.

\begin{tabular}{cccc}
\hline Standard Test Methods & Materials & Temperature & No. of Specimen \\
\hline \multirow{2}{*}{ Tensile test } & $9 \% \mathrm{Ni}$ & R.T. & 3 \\
\cline { 2 - 4 } & High Mn & C.T. & 3 \\
\hline \multirow{2}{*}{$\begin{array}{c}\text { Fracture toughness test } \\
\text { (CTOD) }\end{array}$} & $9 \% \mathrm{Ni}$ & R.T. & 3 \\
\cline { 2 - 4 } Fatigue test & High Mn & C.T. & 3 \\
\cline { 2 - 4 } & $9 \% \mathrm{Ni}$ & R.T. & 12 \\
\hline \multirow{2}{*}{$\begin{array}{c}\text { Fatigue crack growth rate } \\
\text { (FCGR) test }\end{array}$} & High Mn & C.T. & 12 \\
\cline { 2 - 4 } & High Mn & R.T. & 3 \\
\hline
\end{tabular}

The specimen for cryogenic testing was prepared according to ASTM E8/E8M, and the shape of the pin-loaded tension test specimen is shown in Figure 3. The test specimen used in this study was manufactured with a gauge length of $50 \mathrm{~mm}$, a width of $12.5 \mathrm{~mm}$, and a fillet radius of $18.75 \mathrm{~mm}$. Meanwhile, the thickness values of high $\mathrm{Mn}$ steel and $9 \%$ Ni steel were $12 \mathrm{~mm}$ and $8 \mathrm{~mm}$, respectively.

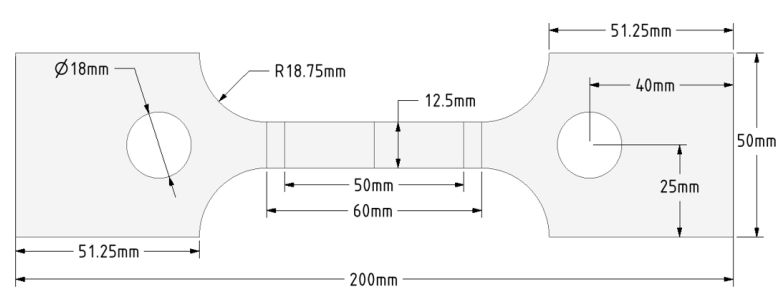

(a)

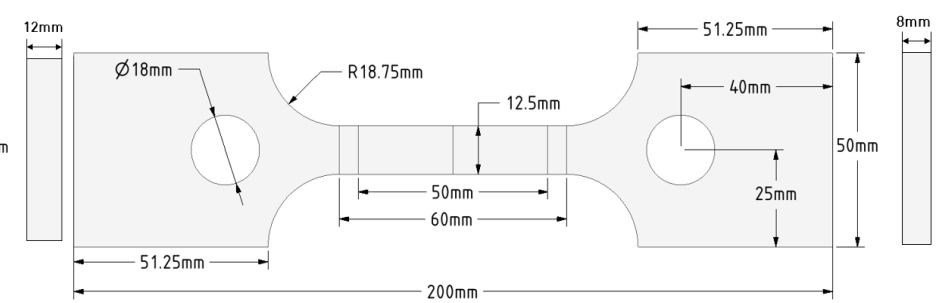

(b)

Figure 3. Detailed dimensions of tensile test specimens: (a) high Mn; (b) $9 \% \mathrm{Ni}$.

In the tensile tests, an extensometer is used to measure the strain rate, and the obtained results are expressed as a stress-strain (S-S) curve. These curves reveal many of the properties of a material, such as the yield strength and ultimate tensile strength, Young's modulus, and elongation.

\subsection{Fracture Toughness Test}

The crack tip opening displacement (CTOD) test, which is a common fracture mechanics test that measures the resistance of a material to growing cracks, is used to determine the fracture mechanics properties of ductile materials. The data obtained from this opening at the crack tip can be used for critical defect assessment, wherein the critical defect size can be calculated.

BS 7448 provides guidelines and procedures for the fracture mechanical toughness tests as a method for determining $K_{I c}$, critical CTOD, and critical $J$ values of the welds in the materials. In this study, the CTOD test was performed according to BS 7448 [21].

As shown in Figure 4, the CTOD test specimens were manufactured as single edgenotched bend (SENB) specimens following BS 7448 and made using the plasma arc-welding (PAW) process. CTOD specimens of high $\mathrm{Mn}$ steel and 9\% Ni steel were respectively manufactured with thicknesses of $12 \mathrm{~mm}$ and $8 \mathrm{~mm}$, widths of $24 \mathrm{~mm}$ and $16 \mathrm{~mm}$, overall lengths of $110.4 \mathrm{~mm}$ and $73.6 \mathrm{~mm}$, and machined notches of $10.5 \mathrm{~mm}$ and $7 \mathrm{~mm}$. The CTOD test is controlled by displacement under quasi-static loading. 


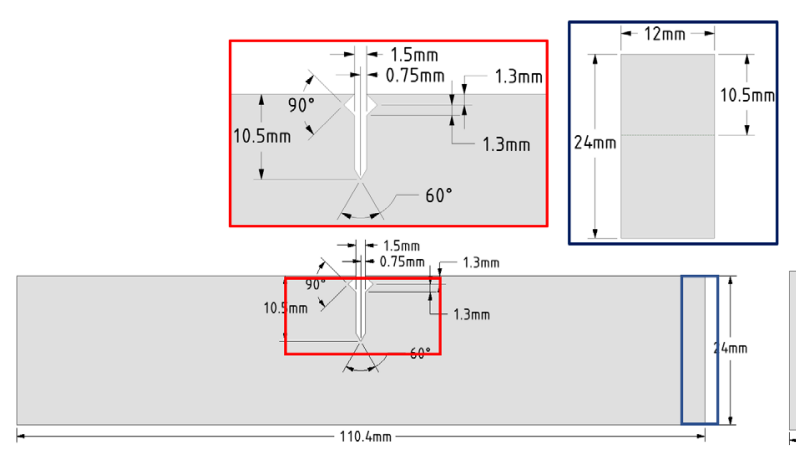

(a)

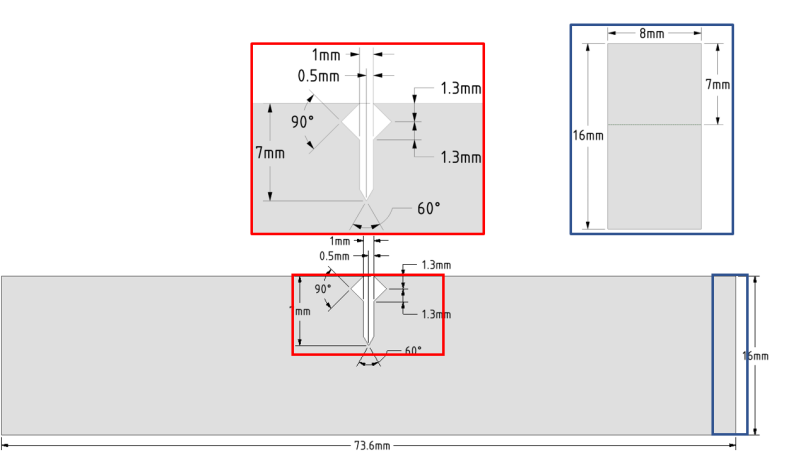

(b)

Figure 4. Detailed dimensions of CTOD test specimens: (a) high Mn; (b) 9\% Ni.

The CTOD value for any point on the force-displacement curve can be calculated using the following expression [21].

$$
\delta=\left[\frac{F S}{B W^{1.5}} \times f\left(\frac{a_{0}}{W}\right)\right]^{2} \frac{\left(1-v^{2}\right)}{2 \sigma_{Y S} E}+\frac{0.4\left(W-a_{0}\right) V_{P}}{0.4 W+0.6 a_{0}+z}
$$

where $S$ is the bending span, $v$ is the Poisson's ratio, $a_{0}$ is the initial crack length, $E$ is the elastic modulus, $z$ is the initial distance of the notch opening gauge measurement position from the notched edge of the specimen, $V_{p}$ is the plastic component of notch opening displacement from the fatigue test record, and $f\left(\frac{a_{0}}{W}\right)$ can be itself determined using the following equation

$$
f\left(\frac{a_{0}}{W}\right)=\frac{3\left(\frac{a_{0}}{W}\right)^{0.5}\left[1.99-\left(\frac{a_{0}}{W}\right)\left(1-\frac{a_{0}}{W}\right)\left(2.15-\frac{3.93 a_{0}}{W}+\frac{2.7 a_{0}^{2}}{W^{2}}\right)\right]}{2\left(1+\frac{2 a_{0}}{W}\right)\left(1-\frac{a_{0}}{W}\right)^{1.5}} .
$$

\subsection{Fatigue Test}

The fatigue test was performed by following the procedure of the axial force-controlled fatigue test to obtain the fatigue strength of cryogenic materials according to ASTM E466 [22]. To minimize the stress concentration factor (SCF) of the specimen, the radius of the fatigue specimen should be at least 8 times its width. The ratio of the width to thickness of the specimen test section should be between 2 and 6 , and the reduced area should preferably be between 19.4 and $645 \mathrm{~mm}^{2}$. In addition, the fatigue test section length should be approximately 2 to 3 times the test section width of the specimen. The dimensions of the fatigue test specimen are shown in Figure 5.

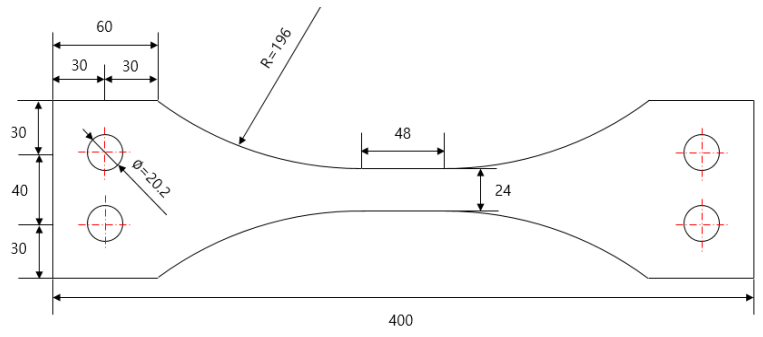

(a)

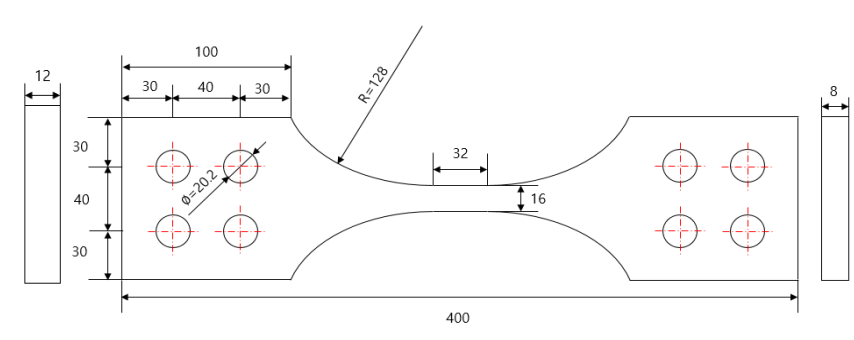

(b)

Figure 5. Detailed dimensions of fatigue test specimens: (a) high Mn; (b) $9 \% \mathrm{Ni}$.

The fatigue test is continued until specimen failure or until a predetermined number of stress cycles have been exceeded. The fatigue failure is defined as complete separation of 
the specimen, a visible crack at the specified magnification, a crack of specified dimensions, or some other criterion.

In the maritime sector where the fatigue performance of welded joints is very important, it is based on the recommendations of the International Institute of Welding (IIW) to ensure the safe operation of welded joints during their effective service life [23]. The S-N curve was derived from the results obtained using the following equation presented in IIW's recommendations of the fatigue design of welded joints and components [24].

$$
\log N=\log C-m \cdot \log \Delta \sigma
$$

where $N$ is the number of fatigue cycles, $\Delta \sigma$ is the stress range, and $m$ is the slope of the $\mathrm{S}-\mathrm{N}$ curve. In the S-N curve, the $Y$-axis is the alternating stress, and the $X$-axis represents the number of cycles $(N)$.

The fatigue design curves are selected by the IIW document according to the geometry of the test specimens. Each fatigue strength S-N curve is identified by the characteristic fatigue strength of the detail in MPa at 2 million cycles. This value is the fatigue class (FAT). The slope of the fatigue strength S-N curves for details assessed on the basis of normal stresses is $m=3$ if not stated expressly otherwise. The fatigue design curve of the butt joint specimen is considered to be FAT 80 class. The fatigue strength of the FAT 80 class at $2 \times 10^{6}$ cycles is $80 \mathrm{MPa}$.

\subsection{Fatigue Crack Growth Rate (FCGR) Test}

The FCGR test was performed according to the procedure described in ASTM E647; this is a standard test method for determining the fatigue crack growth rate [25]. The test specimens were prepared as shown in Figure 6. The specimen orientation was fabricated with a through-thickness notched specimen. The width, $W$, is $80 \mathrm{~mm}$ and the thickness, $B$, is 8 or $12 \mathrm{~mm}$. Furthermore, the diameter of the holes, $D$, is $20 \mathrm{~mm}$, and the length of the machined notch, $a_{n}$, is $36 \mathrm{~mm}$.
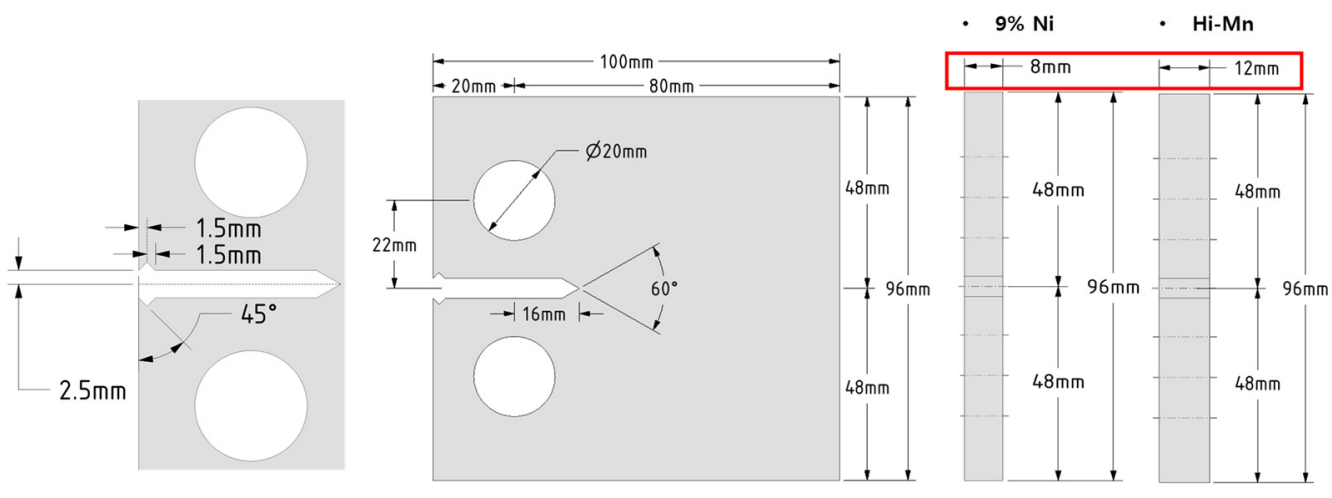

Figure 6. Detailed dimensions of compact tension specimens for the FCGR test.

All FCGR tests were carried out under load control conditions at a stress ratio of 0.1 . The cryogenic test was performed after at least 15 min so that the test specimen could be sufficiently cooled using liquid nitrogen gas. In addition, as a fatigue precracking requirement, the minimum length of a precrack must be at least $0.1 \mathrm{~B}, \mathrm{~h}$, or $1.0 \mathrm{~mm}(0.04 \mathrm{in})$, whichever is greater. Sharp-notch introduction eliminates the notch effect, which affects fatigue crack growth and several additional effects of the crack tip.

During the FCGR test, crack mouth opening displacement (CMOD) is measured using a COD gauge, and the test results are expressed as a $d a / d N-\Delta \mathrm{K}$ curve. Crack growth rates are expressed as a function of the stress-intensity factor range, $\Delta \mathrm{K}$, which is calculated from expressions based on linear elastic stress analysis. $d a / d N$ can be more formally expressed as follows.

$$
(d a / d N)_{\bar{a}}=\left(a_{i+1}-a_{i}\right) /\left(N_{i+1}-N_{i}\right)
$$


where $\bar{a}$ is the average value of the crack size, $a$ is the crack length, and $N$ is the cycle number.

In addition, $\Delta \mathrm{K}$ for the compact tension (CT) specimen is calculated as follows:

$$
\Delta \mathrm{K}=\frac{\Delta P}{B \sqrt{W}} \frac{(2+\alpha)}{(1-\alpha)^{3 / 2}}\left(0.886+4.64 \alpha-13.32 \alpha^{2}+14.72 \alpha^{3}-5.6 \alpha^{4}\right)
$$

where $\alpha$ is $a / W$; the expression is valid for $a / W \geq 0.2$.

\section{Test Results}

\subsection{Tensile Test Results}

The tensile test was conducted on 12 specimens, three each at room and cryogenic temperatures for each of high $\mathrm{Mn}$ steel and 9\% Ni steel. Figure 7 shows photographs of the fractured specimens after the tensile test. Figure 8 presents the stress-strain (S-S) curves for high $\mathrm{Mn}$ steel and $9 \% \mathrm{Ni}$ steel. The tensile test results such as yield strength $\left(\sigma_{\mathrm{YS}}\right)$ and tensile strength $\left(\sigma_{\mathrm{TS}}\right)$ of the weld metals are summarized in Table 5 , and the test results were confirmed based on the minimum value of yield strength.

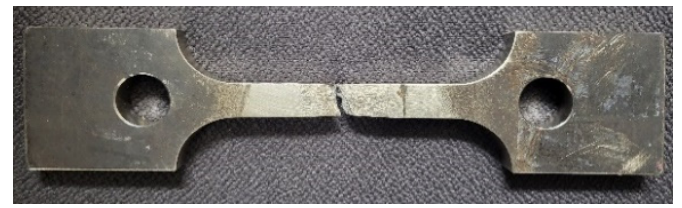

(a)

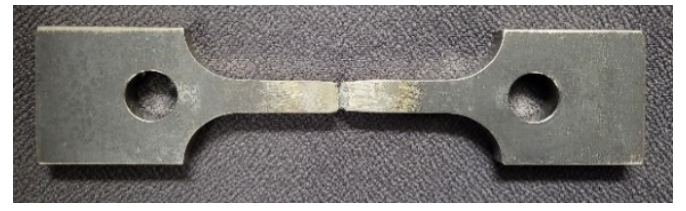

(b)

Figure 7. Tensile test specimens for the weld metals: (a) high Mn; (b) $9 \% \mathrm{Ni}$.

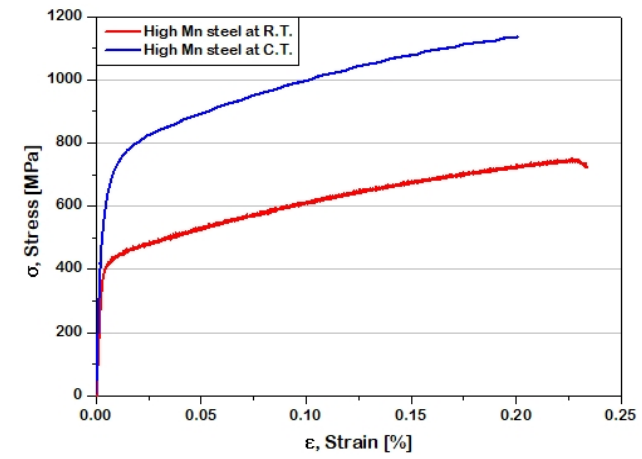

(a)

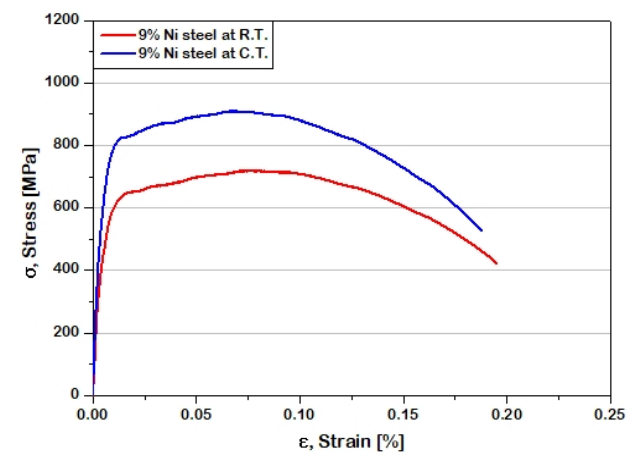

(b)

Figure 8. Stress-strain curves of weld metals at RT and CT: (a) high Mn; (b) 9\% Ni.

Table 5. Tensile test results of the weld metals.

\begin{tabular}{|c|c|c|c|c|c|c|c|}
\hline \multirow[b]{2}{*}{ Material } & \multirow{2}{*}{$\begin{array}{l}\text { Temp. } \\
\text { (K) }\end{array}$} & \multicolumn{3}{|c|}{$\sigma_{\mathrm{YS}}(\mathrm{MPa})$} & \multicolumn{3}{|c|}{$\sigma_{\text {UTS }}(\mathrm{MPa})$} \\
\hline & & Aver. & S.D. & $\begin{array}{c}\text { DNV } \\
\text { Requirement }\end{array}$ & Aver. & S.D. & $\begin{array}{c}\text { DNV } \\
\text { Requirement }\end{array}$ \\
\hline \multirow{2}{*}{ High Mn } & RT (298) & 441.0 & 6.5 & 400 & 741.3 & 2.9 & 800 \\
\hline & CT (110) & 617.0 & 10.3 & - & 1120.4 & 10.3 & - \\
\hline \multirow{2}{*}{$9 \% \mathrm{Ni}$} & RT (298) & 504.0 & 13.6 & 490 & 710.7 & 11.1 & 640 \\
\hline & CT (110) & 606.4 & 23.7 & - & 920.4 & 9.0 & - \\
\hline
\end{tabular}

With decreasing temperatures, the yield strengths of the high Mn steel and $9 \% \mathrm{Ni}$ steel increased by $40 \%$ and $20 \%$, respectively, and the tensile strengths increased by $51 \%$ and 30\%, respectively. This indicates that high $\mathrm{Mn}$ steel and 9\% Ni steel have excellent mechanical properties at cryogenic temperatures. 
The mechanical properties such as the yield strength and tensile strength of the weld metal of $9 \% \mathrm{Ni}$ steel at room temperature satisfy the values recommended by DNV [19]. However, in the case of high Mn steel, while the yield strength satisfies the value required by DNV, the tensile strength is about 7.3\% lower. This is considered to be the effect of a strength mismatch in the weld metal due to the high mechanical properties of high Mn steel, such as its high strength and excellent toughness as a base metal (BM). For butt welds in carbon-manganese steels made by arc welding, John Hicks suggests that it may not be possible or feasible to produce a weld metal of matching strength, and so a weld metal of lower strength than the base metal may have to be accepted [26]. According to resolution MSC.370 (93) adopted in the International Gas Carrier (IGC) code of the International Maritime Organization (IMO), if the performance of the weld metal is lower than that of the base metal, then the design is based on the performance of the weld metal [27]. Therefore, it can be said that if the strength of the base metal is higher than that of the weld metal, it is necessary to apply undermatched welded joints to improve weldability.

Considering that the steel used in this study is for cryogenic temperatures, it can be confirmed that the mechanical properties are very stable at cryogenic temperatures. Although the tensile strength of high Mn steel at room temperature did not satisfy the value requirement by $\mathrm{DNV}$, considering that this study is a prior study for the application of plasma arc welding, it seems to be possible to improve the tensile properties of the high Mn steels at room temperature through additional studies such as improvement of the welding process. It is expected that plasma arc welding can be applied to both steels.

\subsection{Fracture Toughness Test Results}

The CTOD test was conducted on 12 specimens, three each at room and cryogenic temperatures for each of high Mn steel and 9\% Ni steel. Figure 9 shows photographs of the fractured specimens after the CTOD test. Figure 10 shows a comparison of the CTOD values of weld metals for high Mn steel and 9\% Ni steel in the PAW process.

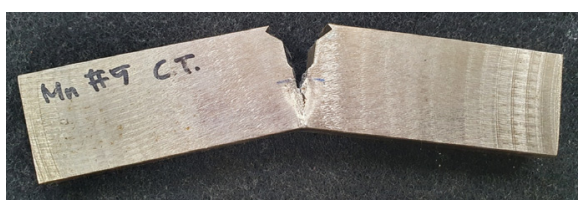

(a)

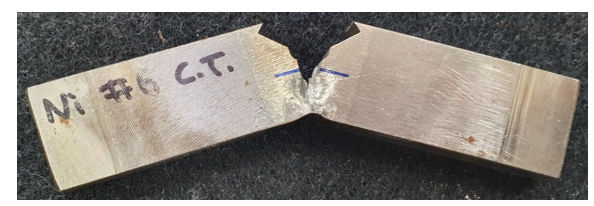

(b)

Figure 9. CTOD test specimens for the weld metals: (a) high Mn; (b) $9 \% \mathrm{Ni}$.

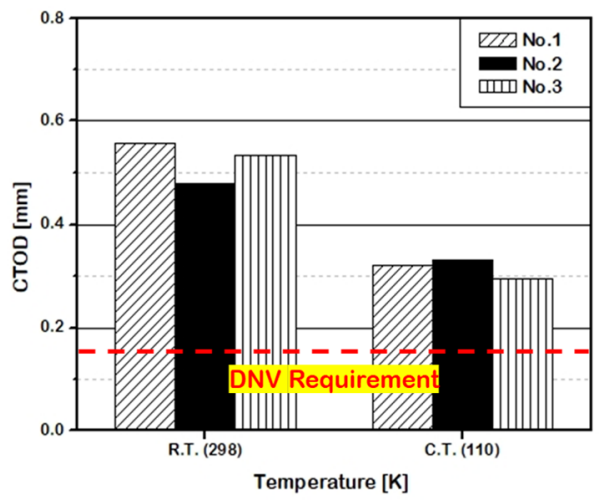

(a)

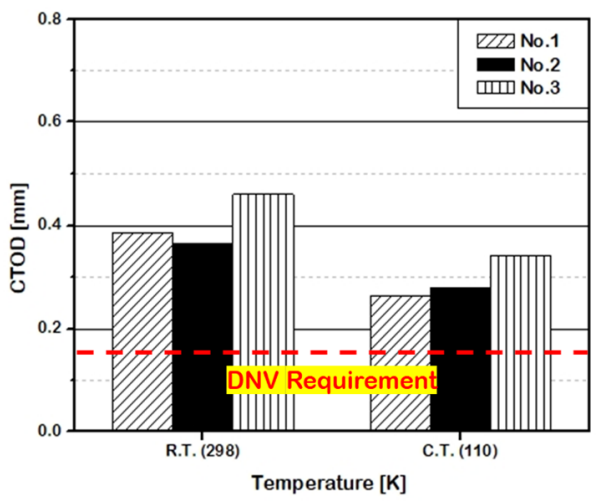

(b)

Figure 10. CTOD test results of weld metals: (a) high $\mathrm{Mn}$; (b) $9 \% \mathrm{Ni}$.

The results show that the CTOD values of all weld metals decreased at cryogenic temperatures. This is attributed to the fact that for both steels, the fracture resistance of the weld metal decreases as the temperature drops from room temperature to cryogenic 
temperature. The minimum CTOD values of $9 \% \mathrm{Ni}$ steel were the lowest at both room temperature and cryogenic temperature, but the CTOD value showed a similar tendency according to temperature as that of high Mn steel. DNV suggests that the critical CTOD for all tested specimens should be equal to or larger than $0.15 \mathrm{~mm}$ [28]. In the results of this study, all CTOD values of weld metals at room and cryogenic temperatures met $0.15 \mathrm{~mm}$, thus satisfying the values recommended by DNV.

\subsection{Fatigue Test Results}

The fatigue test was conducted on 48 specimens, 12 each at room and cryogenic temperatures for each of high $\mathrm{Mn}$ steel and 9\% Ni steel. The fatigue loading conditions were divided into five to seven stages based on tensile strength. The stress ratio of cyclic loading was determined to be $0.1(R=0.1)$ under load control conditions at room and cryogenic temperatures. The fatigue limit was based on the fatigue strength at $2 \times 10^{6}$ cycles (FAT), and specimens with a fatigue life exceeding $2 \times 10^{6}$ cycles were excluded from the S-N curve fitting.

Figure 11 shows photographs of the fractured specimens after the fatigue test. For the fatigue test results, the S-N curve, which was derived according to the procedure presented in the IIW document, is shown in Figure 12 [24]. The solid black line in Figure 12 indicates the IIW FAT 80 weld detail class for butt joints at a survival probability of $97.7 \%$. In the case of $9 \% \mathrm{Ni}$ steel, the fatigue strengths at the environments of room and cryogenic temperatures are 84.2 $\mathrm{MPa}$ and $108.5 \mathrm{MPa}$, respectively. Meanwhile, high-Mn steel showed corresponding values of $88.2 \mathrm{MPa}$ and $90.4 \mathrm{MPa}$, respectively.

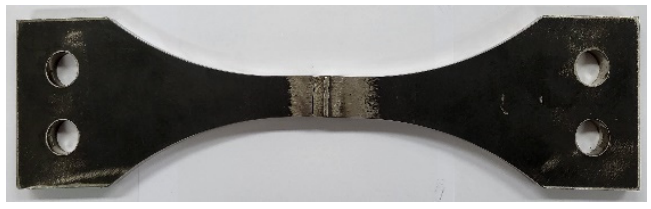

(a)

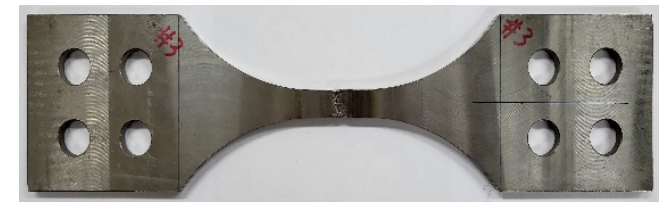

(b)

Figure 11. Fatigue test specimens for the weld metals: (a) high Mn; (b) $9 \% \mathrm{Ni}$.

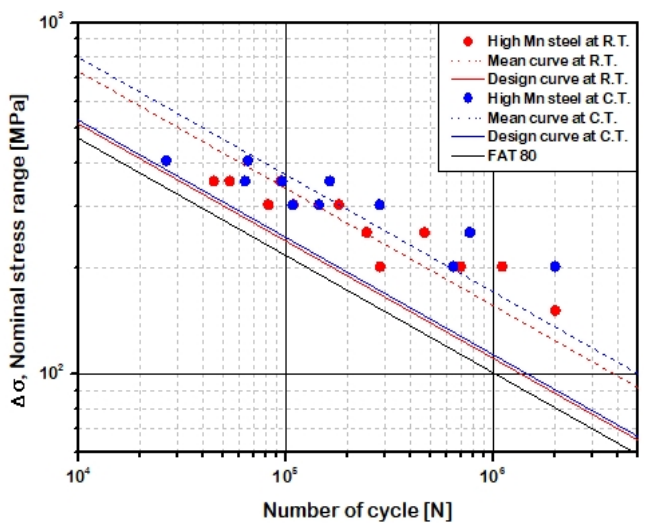

(a)

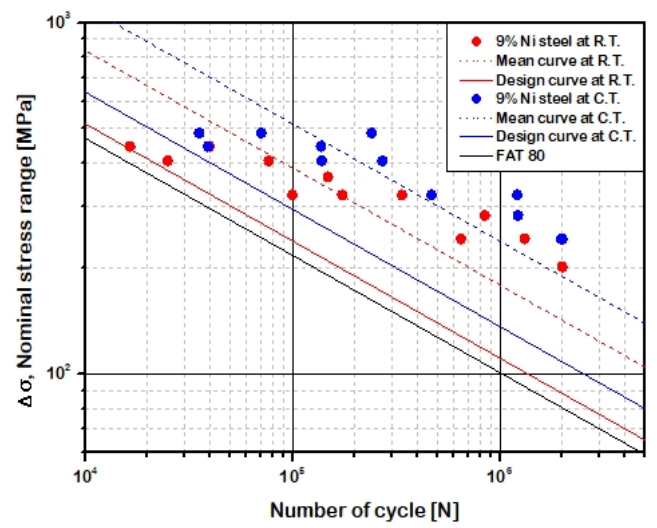

(b)

Figure 12. S-N curve of the weld metals compared to the IIW FAT 80 class: (a) high Mn; (b) 9\% Ni.

The fatigue test results in Figure 12 show higher fatigue strength in all samples compared to the IIW FAT 80 class. Therefore, the S-N curve of butt joints with plasma arc welding is observed to satisfy the IIW FAT 80 class.

Table 6 summarizes the standard deviation values from the fatigue test results of high Mn steel and 9\% Ni steel. As presented in Figure 12, the fatigue test data of 9\% Ni steel showed a wide scatter compared to that of high-Mn steel. In the standard deviation, only the quantitative dispersion of each data is considered, so the standard deviation is 
calculated to be large as the fatigue life cycle increases. Therefore, both steels showed a higher standard deviation at cryogenic temperature compared to room temperature. As presented in the Table 6 , the fatigue data of $9 \% \mathrm{Ni}$ steel at cryogenic temperature showed the highest standard deviation in this study.

Table 6. The standard deviation for fatigue data of weld metals.

\begin{tabular}{cccc}
\hline \multicolumn{3}{c}{ High Mn } & \multicolumn{2}{c}{$\mathbf{9 \% ~ N i}$} \\
\hline RT (298 K) & CT (110 K) & RT (298 K) & CT (110 K) \\
\hline 0.224 & 0.267 & 0.343 & 0.364 \\
\hline
\end{tabular}

\subsection{FCGR Test Results}

The FCGR test was conducted on 12 specimens, three each at room and cryogenic temperatures for each of high-Mn steel and $9 \% \mathrm{Ni}$ steel. Figure 13 shows photographs of the fractured specimens after the FCGR test. In addition, representative $d a / d N-\Delta \mathrm{K}$ curves of all locations are shown in Figure 14. The material constants of the weld metals with PAW are summarized in Table 7.

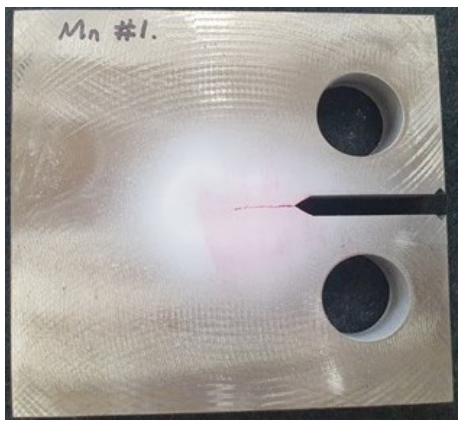

(a)

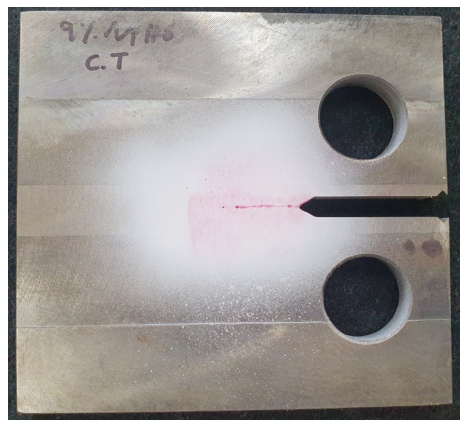

(b)

Figure 13. FCGR test specimens for weld metals: (a) high Mn; (b) 9\% Ni.

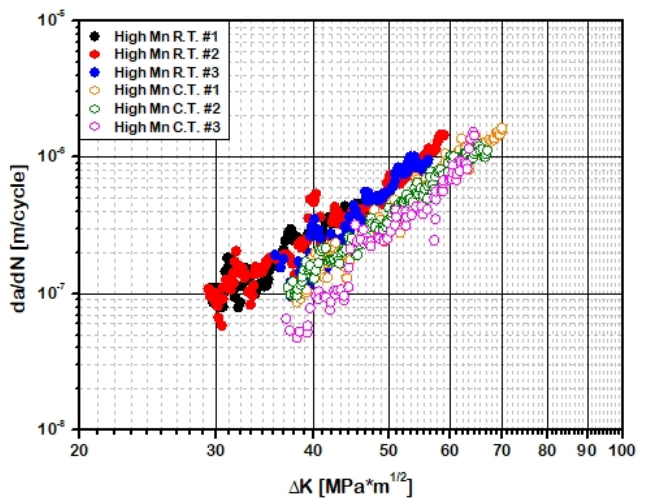

(a)

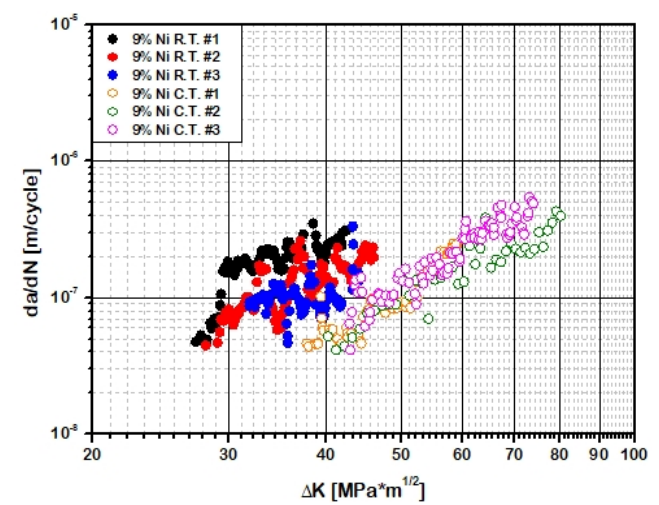

(b)

Figure 14. $d a / d N-\Delta \mathrm{K}$ curves of weld metals: (a) high Mn; (b) $9 \% \mathrm{Ni}$.

The FCGR test on high-Mn steel and 9\% Ni steel according to ASTM E647 confirmed that the $c$ value, which is the initial crack growth rate, was low for both steels as the temperature decreased. However, the $m$ value, which is the slope of the crack growth rate, increased. Therefore, it can be seen that the initial crack growth rate is slow as the ambient temperature decreases, but that the slope of the crack growth rate increases.

When the crack growth rates of the two steels were compared with each other under the same temperature, the initial crack growth rate of the high Mn steel was slower, but 
the slope of the crack propagation rate was higher. This means that the slope $m$ value of the crack growth rate of high Mn steel was higher than that of $9 \% \mathrm{Ni}$ steel, while its initial crack growth rate $c$ value was lower.

Table 7. FCGR test results of weld metals.

\begin{tabular}{cccc}
\hline Material & Temperature (K) & $\boldsymbol{m}$ & c (m/cycle) \\
\hline \multirow{2}{*}{ High Mn } & RT (298) & 3.913 & $1.274 \times 10^{-13}$ \\
\cline { 2 - 4 } & CT (110) & 4.848 & $1.866 \times 10^{-15}$ \\
\hline \multirow{2}{*}{$9 \% \mathrm{Ni}$} & $\mathrm{RT}(298)$ & 1.838 & $1.807 \times 10^{-10}$ \\
\cline { 2 - 4 } & $\mathrm{CT}(110)$ & 3.517 & $1.067 \times 10^{-13}$ \\
\hline
\end{tabular}

The crack growth rate slopes $m$ of high Mn steel were about 2.1 times and about 1.4 times higher than those of $9 \% \mathrm{Ni}$ steel at room and cryogenic temperatures, respectively. As a result, the FCGR values of all weld metals were found to decrease with decreasing temperature.

Figure 15 shows a comparison of the test results obtained in this study with the fatigue crack propagation rate $(d a / d N)$ of the austenite series presented in BS 7910 [29]. To compare the test results of the fatigue crack growth rate, the material constant $m$ was fixed to 3 , as suggested in BS 7910, and the design curves according to the test conditions were shown using the derived value $c$ and standard deviation. The design curves (mean $+2 \mathrm{SD}$ ) of the weld metals are shown in Figure 15.

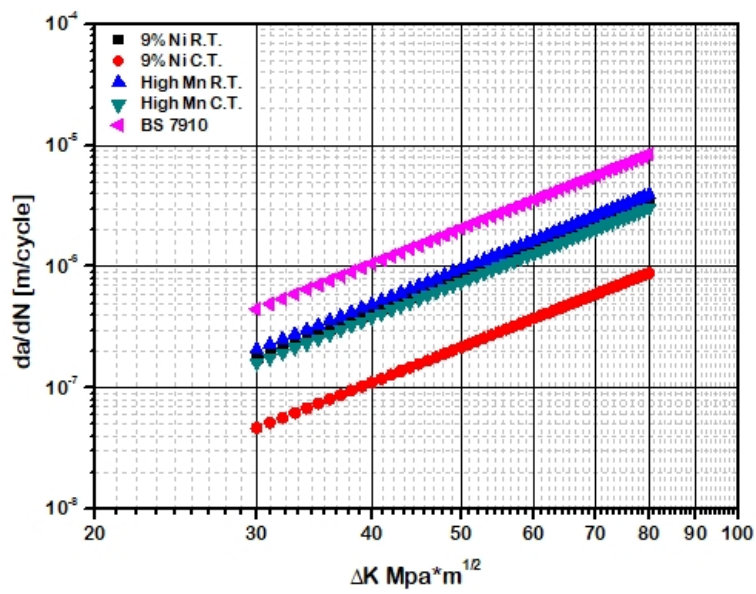

Figure 15. $d a / d N-\Delta \mathrm{K}$ curves of the weld metals compared to the BS 7910 (mean +2 SD curve).

The test results indicated that the crack propagation rate of $9 \%$ Ni steel was the slowest in the cryogenic environment, and that high-Mn steel showed the fastest rate at room temperature. It can be seen that the crack propagation rates of high-Mn steel and $9 \% \mathrm{Ni}$ steel at room and cryogenic temperatures are slower than those in the conservative reference curves of BS 7910.

In addition, all tested cryogenic materials showed excellent results in terms of crack propagation. The material constants (fitted with the slope of the crack propagation rate, $m=3$ ) for the weld metals of high-Mn steel and 9\% Ni steel are summarized in Table 8. 
Table 8. Comparison of material constants for the weld metals.

\begin{tabular}{|c|c|c|c|c|}
\hline Type & Material & $\begin{array}{c}\text { Temperature } \\
\text { (K) }\end{array}$ & $m$ & c (m/cycle) \\
\hline \multirow{5}{*}{$\begin{array}{c}\text { Design curve } \\
(\text { Mean + } 2 \text { SD) }\end{array}$} & \multirow{2}{*}{ High Mn } & RT (298) & \multirow{5}{*}{3} & $3.864 \times 10^{-12}$ \\
\hline & & CT (110) & & $2.570 \times 10^{-12}$ \\
\hline & \multirow{2}{*}{$9 \% \mathrm{Ni}$} & RT (298) & & $2.831 \times 10^{-12}$ \\
\hline & & CT (110) & & $8.472 \times 10^{-13}$ \\
\hline & BS 7910 & RT (298) & & $1.650 \times 10^{-11}$ \\
\hline
\end{tabular}

\section{Conclusions}

In this work, an experimental study investigating fatigue and fracture performances of welded joints was conducted by applying plasma arc welding to high-Mn steel and $9 \% \mathrm{Ni}$ steel to be used in LNG fuel storage tanks. The main results of this study can be summarized as follows:

- In the tensile test results, the effect of temperature was confirmed based on the minimum value of ultimate tensile strength. As the temperatures of the high-Mn steel and $9 \% \mathrm{Ni}$ steel decreased, the yield strengths increased by $40 \%$ and $20 \%$, respectively, and the tensile strengths increased by $51 \%$ and $30 \%$, respectively. This indicates that the mechanical properties of both steels are excellent at low temperature. In addition, high-Mn steel and 9\% Ni steel both satisfy the mechanical properties recommended by DNV rules in terms of the minimum value of yield strength.

- After performing the CTOD test according to BS 7448, the CTOD values of all weld metals decreased at cryogenic temperatures. This is attributed to the fact that the fracture resistance of the weld metals decreases under the influence of temperature. In addition, all CTOD values of weld metals at room and cryogenic temperature met $0.15 \mathrm{~mm}$, thus satisfying the values recommended by DNV.

- For the fatigue test results, the S-N curve of butt joints with plasma arc welding is observed to satisfy the IIW FAT 80 class. Comparing fatigue strength, that of high-Mn steel was found to be about $5 \%$ higher at room temperature; meanwhile, at cryogenic temperature, the fatigue strength of $9 \% \mathrm{Ni}$ steel was about $20 \%$ higher than that of high $\mathrm{Mn}$ steel. In addition, the fatigue data of $9 \% \mathrm{Ni}$ steel at cryogenic temperature showed the highest standard deviation.

- $\quad$ ASTM E647 suggests that data are valid when the angle between the crack generated through the FCGR test and the preliminary fatigue crack is less than $10^{\circ}$. The angles of cracks generated through this test were all less than $10^{\circ}$, and the design curves of high-Mn steel and $9 \% \mathrm{Ni}$ steel both satisfy the crack growth rate criteria for austenitic steels presented in BS 7910.

- This study was conducted as a preliminary study for the application of automatic plasma arc welding to cryogenic materials in LNG fuel storage tanks for coastal ships. Therefore, this study confirmed the applicability of PAW, and additional studies are planned to improve the stability of the PAW process so that it can be applied in practice in the future.

Author Contributions: Conceptualization, T.-Y.K., M.-H.K. and S.-W.Y.; methodology, T.-Y.K.; validation, T.-Y.K., M.-H.K. and S.-W.Y.; formal analysis, T.-Y.K.; investigation, T.-Y.K. and J.-H.K.; resources, T.-Y.K.; data curation, T.-Y.K. and J.-H.K.; writing-original draft preparation, T.-Y.K.; writing-review and editing, T.-Y.K. and S.-W.Y.; visualization, T.-Y.K.; project administration, S.-W.Y. All authors have read and agreed to the published version of the manuscript.

Funding: This work was supported by the Technology Innovation Program (No. 20004935, Development of Small and Medium Sized LNG Fuel Storage Module for Coastal Ships) funded by the Ministry of Trade, Industry and Energy (MOTIE) of the Republic of Korea. 
Institutional Review Board Statement: Not applicable.

Informed Consent Statement: Not applicable.

Conflicts of Interest: The authors declare no conflict of interest.

\section{References}

1. DNV Managing Risk. MARPOL 73/78 Annex VI: Regulations for the Prevention of Air Pollution from Ships-Technical and Operational Implications; Det Norske Veritas (DNV): Oslo, Norway, 2015; Volume 14.

2. Saitoh, N.; Yamaba, R.; Muraoka, H.; Saeki, O. Development of Heavy 9\% Nickel Steel Plates with Superior Low-Temperature Toughness for LNG Storage Tanks; Nippon Steel: Tokyo, Japan, 1993.

3. Yoon, Y.K.; Kim, J.H.; Shim, K.T. Mechanical characteristics of $9 \%$ Ni steel welded joint for LNG storage tank at cryogenic. Int. J. Mod. Phys. Conf. Ser. 2012, 6, 355-360. [CrossRef]

4. Kim, B.E.; Park, J.Y.; Lee, J.S.; Lee, J.I.; Kim, M.H. Effects of the welding process and consumables on the fracture behavior of 9 wt.\% nickel steel. Exp. Tech. 2019, 44, 175-186. [CrossRef]

5. Kim, B.E.; Park, J.Y.; Lee, J.S.; Kim, M.H. Study on the Initial Design of an LNG Fuel Tank using 9 wt.\% Nickel Steel for Ships and Performance Evaluation of the Welded Joint. J. Weld. Join. 2019, 37, 555-563. [CrossRef]

6. Kim, J.W.; Kim, J.S.; Kang, S.W.; Chun, K.S. Laser welding of ASTM A553-1 (9\% Nickel Steel) (PART I: Penetration shape by bead on plate). Metals 2020, 10, 484. [CrossRef]

7. Kim, J.W.; Kim, J.S. Laser Welding of ASTM A553-1 (9\% Nickel Steel) (PART II Comparison of Mechanical Properties with FCAW). Metals 2020, 10, 999. [CrossRef]

8. Oh, D.J.; Kim, N.K.; Song, S.W.; Kim, Y.D.; Kim, M.H. Investigation of fatigue performance for new membrane-type LNG CCS at cryogenic temperature. J. Marstruc. 2018, 62, 90-105. [CrossRef]

9. Choi, J.K.; Lee, S.G.; Park, Y.H.; Han, I.W.; Morris, J.W. High manganese austenitic steel for cryogenic applications. In Proceedings of the Twenty-second International Offshore and Polar Engineering Conference, Rhodes, Greece, 17-22 June 2012.

10. Fan, X.; Li, Y.; Qi, Y.; Cai, X.; Wang, Z.; Ma, C. Mechanical properties of cryogenic high manganese steel joints filled with nickel-based materials by SMAW and SAW. Mater. Lett. 2021, 304, 130596. [CrossRef]

11. Seo, W.G.; Jeong, D.H.; Sunng, H.K.; Kim, S.S. Tensile and high cycle fatigue behaviors of high-Mn steels at 298 and $110 \mathrm{~K}$ Mater. Charact. 2017, 124, 65-72. [CrossRef]

12. Jeong, D.H.; Park, T.D.; Lee, J.S.; Kim, S.S. Ambient and cryogenic S-N fatigue behavior of Fe15Mn steel and its weld. Met. Mater. Int. 2015, 21, 453-460. [CrossRef]

13. Park, J.H.; Lee, K.H.; Sung, H.K.; Kim, Y.J.; Kim, S.K.; Kim, S.S. J-integral fracture toughness of high-Mn steels at room and cryogenic temperatures. Metall. Mater. Trans. A 2019, 50, 2678-2689. [CrossRef]

14. Park, G.W.; Jo, H.; Park, M.; Kim, B.J.; Lee, W.; Shin, S.; Park, S.S.; Ahn, Y.S.; Jeon, J.B. Effect of Heat Treatment and Drawing on High-Manganese Steel Pipe Welded by Gas Tungsten Arc. Metals 2020, 10, 1366. [CrossRef]

15. Park, G.W.; Jo, H.; Park, M.; Shin, S.; Ko, W.S.; Park, N.; Kim, B.J.; Ahn, Y.S.; Jeon, J.B. Microstructure and Mechanical Properties of Gas Tungsten Arc Welded High Manganese Steel Sheet. Metals 2019, 9, 1167. [CrossRef]

16. Fatima, S.; Khan, M.; Jaffery, S.H.I.; Ali, L.; Mujahid, M.; Butt, S.I. Optimization of process parameters for plasma arc welding of austenitic stainless steel (304L) with low carbon steel (A-36). Proc. Inst. Mech. Eng. Part L J. Mater. Des. Appl. 2015, $230,640-653$.

17. Sahoo, A.; Tripathy, S. Development in plasma arc welding process: A review. Mater. Today Proc. 2021, 41, 363-368. [CrossRef]

18. ASTM International. ASTM A1106/A1106M-17: Standard Specification for Pressure Vessel Plate, Alloy Steel, Austenitic High Manganese for Cryogenic Application; American Society for Testing and Materials (ASTM): West Conshohocken, PA, USA, 2017.

19. DNV Maritime. Rules for Classification-Part 2 Chapter 2 Metallic Materials; Det Norske Veritas (DNV): Oslo, Norway, 2021.

20. ASTM International. ASTM E8/E8M-16a: Standard Test Methods for Tension Testing of Metallic Materials; American Society for Testing and Materials (ASTM): West Conshohocken, PA, USA, 2016.

21. British Standard. BS 7448 - Part 1: Fracture Mechanics Toughness Test. Part 1. Method for Determination of KIc, Critical CTOD and Critical J Values of Metallic Materials; British Standard Institution (BSI): London, UK, 1991; pp. 25-27.

22. ASTM International. ASTM E466-15: Standard Practice for Conducting Force Controlled Constant Amplitude Axial Fatigue Tests of Metallic Materials; American Society for Testing and Materials (ASTM): West Conshohocken, PA, USA, 2015.

23. Toumpis, A.I.; Galloway, A.M.; Camilleri, D.; Arbaoui, L. Recent Developments in Steel Friction Stir Welding: Project HILDA. In Proceedings of the ASME 2015 International Mechanical Engineering Congress and Exposition, Houston, TX, USA, 13-19 November 2015. IMECE2015-51349.

24. Hobbacher, A. IIW-1823-07/XIII-2151r4-07/XV-1254r4-07: Recommendations for Fatigue Design of Welded Joints and Components; International Institute of Welding (IIW): Paris, France, 2008; p. 94.

25. ASTM International. ASTM E647-13a: Standard Test Method for Measurement of Fatigue Crack Growth Rates; American Society for Testing and Materials (ASTM): West Conshohocken, PA, USA, 2013.

26. Hicks, J. Theory and Practice. In Welded Design, 1st ed.; Abington Publishing: Cambridge, UK, 2000.

27. IMO. Resolution MSC.370(93): International Code for the Construction and Equipment of Ships Carrying Liquefied Gases in Bulk (IGC Code); International Maritime Organization (IMO): London, UK, 2014. 
28. DNV Maritime. Offshore Standards (OS)-C401 Fabrication and Testing of Offshore Structures; Det Norske Veritas (DNV): Oslo, Norway, 2021.

29. British Standard. BS 7910:2013: Guide to Methods for Assessing the Acceptability of Flaws in Metallic Structures; British Standard Institution (BSI): London, UK, 2013. 